Original Research Paper

\title{
Can Emotional Stability Buffer the Effect of Job Stress on Deviant Behavior?
}

\author{
${ }^{1}$ Aminah Ahmad, ${ }^{2}$ Zoharah Omar, ${ }^{2}$ Farah Mardiana Radzali and ${ }^{1}$ Mohammed Bashir Saidu \\ ${ }^{1}$ Institute for Social Science Studies, Universiti Putra Malaysia, 43400 UPM Serdang, Selangor, Malaysia \\ ${ }^{2}$ Faculty of Educational Studies, Universiti Putra Malaysia, 43400 UPM Serdang, Selangor, Malaysia
}

Article history

Received: 26-01-2017

Revised: $20-05-2017$

Accepted: 23-06-2017

Corresponding Author: Aminah Ahmad

Institute for Social Science

Studies, Universiti Putra

Malaysia, 43400 UPM Serdang,

Selangor, Malaysia

Tel: $+603-89471871$

h/p: 012-3683411

Fax: $+603-89471856$

Email: aminahahmad49@gmail.com

\begin{abstract}
The interrelationships between job stress, WDB and emotional stability have not been studied in a model to comprehend whether emotional stability could weaken the impact of job stress on employee deviant behavior. We tested a model on the moderating role of emotional stability, a personality factor, in the relationship between job stress and workplace deviant behavior. The model was developed based on the general strain theory and the integrated general model of workplace deviant behavior. Structural equation modeling analysis was conducted on survey data from 261 employees from six Malaysian public service agencies. Our results supported the proposed model. The stress-deviance relationship is significant. The stress-deviance linkage is stronger among employees who are less emotionally stable than those who are more emotionally stable. The results suggest that emotional stability as a personality factor plays a vital role in further understanding the impact of job stress on employee deviant behavior. Based on the results, the general strain theory and the integrated general model of workplace deviant behavior could serve as the bases for explaining the stress-deviance relationship and the moderating role of emotional stability.
\end{abstract}

Keywords: Job Stress, Deviant Behavior, Counterproductive Work Behavior, Emotional Stability

\section{Introduction}

Acknowledging the negative consequences of workplace deviant behavior (WDB), organizations have considered WDB as a serious matter. An organization's performance and well-being have been negatively affected by WDB (Resick et al., 2013; Tuna et al., 2016). Other negative consequences include high production costs, inconsistent service quality and pricing, poor service reputation and loss of revenue and profits, (Biron, 2010; Nasir and Bashir, 2012). Besides, the physical and mental health of victims of WDB are affected (Nielsen and Knardahl, 2015).

It must be recognized that although the focus of WDB studies has been relatively more on its consequences compared to its predictors (Piquero and Moffitt, 2014; Wei and $\mathrm{Si}, 2013$ ), there is a growing interest on its predictors among researchers. The predictors include personality or dispositional (Fida et al., 2015; O'Neill and Hastings, 2011), organizational (Demir, 2011) and job-related factors (Roberts et al., 2011). With regard to job-related predictors, job stress is increasingly common. Due to the increasing expectations on work performance, employees are working longer hours, assuming greater responsibilities and working extra hard. Hence, it is not surprising to learn that studies have identified stress at work with its negative consequences as a contemporary health issue that should be given serious attention. One of the consequences of job stress is WDB (Roberts et al., 2011). Additionally, employees with low emotional stability tend to engage in deviant behavior (Penney et al., 2011). However, the interrelationships between job stress, WDB and emotional stability have not been studied in a model to comprehend whether emotional stability could weaken the impact of job stress on employee deviant behavior.

Therefore, this study aimed to investigate whether differences in emotional stability can buffer the stressdeviance linkage. Firstly, we propose that job stress will be significantly related to WDB. Secondly, the link between job stress and WDB will depend upon the emotional stability of employees, whereby the experience of stress at work can result in WDB more among employees with low emotional stability than those with high emotional stability. 
The contribution of this investigation to literature on deviance behavior and organizational practice is twofold. First, we use the General Strain Theory (GST) and the integrated general model of WDB to build a model on the interaction of stress and personality and explain how we expect the linkage between job stress and WDB to differ as a function of emotional stability which acts as a buffer in this linkage. Second, the explanation on how emotional stability modifies the stress-deviance linkage by weakening the deleterious effect of job stress on deviant behavior may be useful to employers, particularly in their efforts to reduce employee deviance through personalitybased selection procedure during recruitment.

\section{Workplace Deviant Behavior}

WDB refers to voluntary behavior that infringes significant organizational norms and hence threatens the organization's and/or its members' wellbeing (Robinson and Bennett, 2000), WDB includes for example absenteeism, withholding effort or deliberately working at a slow pace, clocking out at work early, practicing favoritism, theft, harmful conduct towards coworkers, privilege abuse and corruption. Other synonymous WDB terms used in literature include for example counterproductive work behavior by Sackett (2002), insidious behavior by Greenberg (2010) and uncivil behavior by Roberts et al. (2011). Appelbaum et al. (2007) suggested two categories of deviance, namely constructive and destructive deviance. Constructive deviance denotes an employee's innovative behavior that is beneficial to the organization. This paper however, focuses on destructive deviance which reflects an employee's intentional behavior that is harmful to the organization and its members.

\section{Theoretical Background}

The GST (Agnew, 2006) serves as the theoretical foundation for explaining the stress-deviance relationship. The GST postulates that strain-related events result in stressful experiences that encourage the individual to engage in deviant behavior. There is a broad range of strain-related factors and this theory predicts that individuals react to strain in many ways. One of the ways is through deviant behaviors since the stressors results in negative emotional buildups that require remedial action. According to Hay et al. (2010), most studies using GST as the theoretical background have examined crime conducts towards others such as theft and violence. The GST was further advanced by introducing conditioning factors that influence individual's adaption of strain through deviant or other forms of non-deviant behaviors.

Stressors, including job stress, are likely to reduce when there are social resources such as social support, psychological resources such as self-esteem and personal traits such as interpersonal skills (Schieman and Bierman,
2011). This paper considers emotional stability as a psychological resource that strengthens one's coping ability and thus safeguards against the effects of job stress influencing WDB. Drawing from the GST, we postulated that stress experienced at work could foster deviant behavior and this stress-deviance relationship could be buffered by emotional stability.

\section{Job Stress and Workplace Deviant Behavior}

McVicar, (2003) defined job stress as the response resulting from the discrepancy between the expected role outcome and the accomplished role. Roberts et al. (2011) studied WDB, labeled as uncivil behavior, among employees in several industries in the United States. The experience of job stress was found to increase employees' propensity to display uncivil behaviors. Another study of North American, Asian and Indian employees revealed that employees experiencing job stress tend to find a way to forget stress by engaging in non-work related computing which is a form of deviant behavior (Ugrin et al., 2008). The stress-deviance relationship has been demonstrated by Garrett and James's (2008) study among employees in the United States whereby stress led to engagement in the deviant behavior of cyberslacking. Building on these findings, we develop our first hypothesis:

Hypothesis 1: Job stress is positively related to WDB

\section{Emotional Stability as a Moderator}

According to the integrated general model of WDB proposed by Nair and Bhatnagar (2011), besides organizational factors, dispositional factors such as emotional stability is associated with workplace deviant behavior. Emotional stability has been defined as the extent to which individuals can be calm and stable under pressure and are less likely to encounter negative emotional states, such as anxiety, depression and anger (Costa and MacCrae, 1992).

A less emotionally stable individual tends to exhibit deviant behavior (Gonzalez-Mulé et al., 2013; Hudson et al., 2012) such as poor work attitude, tardiness, absenteeism and withholding effort. Nair and Bhatnagar (2011) proposed an integrated general model of WDB, in which, besides organizational factors, individual factors including dispositional factors are associated with WDB. Based on the general strain theory and the integrated general model of WDB as well as previous research findings, we hypothesize the following.

Hypothesis 2: The linkage between job stress and WDB will be more prominent when the emotional stability of employees is low instead of high 


\section{Methodology}

\section{Sample}

The study sample consisted of 261 Malaysian public service employees. In the public sector, despite the commitment to promote civility through the formation of the Public Complaints Bureau and civility improvements achieved in this sector, there is still a need to reduce employee negative behavior as indicated by the substantial complaints received from the public (PCBAR, 2011). We exclude the part-time employees from the sample since the difference in workload may influence the extent of job stress experienced. Using the self-administered structured questionnaire, data were gathered via the drop and collect procedure. In this present study the questions were in Malay, the first language of Malaysians, as well as in English, the second language. The original questions (in English), were translated to the Malay language and then back translated to ensure that the questions have equivalent meanings. We assured the participants that all responses would be kept confidential.

\section{Measures}

\section{Workplace Deviant Behavior}

To assess WDB, 15 items from Robinson and Bennett's (2000) measuring scale were used. Employees indicate how often they engage in deviant behavior using a rating scale from 1 (never) to 7 (very often). The WDB scale comprised of two dimensions namely, interpersonal deviant behaviors-harmful to other individuals in the organization and organizational deviant behaviorsharmful to the organization. Dalal (2005) in a metaanalysis, suggested that the two dimensions be pooled into an overall measure of WDB since the corrected correlation between the two dimensions is reasonably high $(\rho=0.70)$. Gill et al. (2011) also obtained a strong correlation between the two dimensions $(r=0.85)$. Hence, we summed the items and treated this scale as measuring a single WDB construct. Sample items are "Made fun of someone at work" and "Intentionally worked slower than you could have worked".

\section{Job Stress}

To measure job stress, we used seven items from the stress scale by Anderson et al. (2002). Participants were requested to indicate how often they experience stressful feelings or situations using a scale from 1 (never) to 7 (very often). Examples of items are "Have you felt nervous and stressed?" and "Have you found that you could not cope with all the things you had to do?"

\section{Emotional Stability}

We assess emotional stability, as one of the Big Five factors, using five items from the emotional stability scale by Saucier (1994), a shorter version of Goldberg's Big Five Markers. We use the seven-point rating scale ranging from 1 (does not describe me) to 7 (truly describes me). Sample items are "I am fretful" and "I am irritable". All the five items were negative and they were reverse-coded.

\section{Social Desirability Bias}

Social desirability bias denotes the tendency for individuals to portray themselves in a favorable fashion (Tourangeau and Ting, 2007). Since employees in this study are requested to indicate whether the statements described themselves, they may have the tendency not to provide the true picture of themselves. Thus we conducted the social desirability bias test to address this limitation. Social desirability test scores among individuals and in different contexts may vary. The scores were summated whereby a higher score shows an individual's higher social desirability bias. The ten-item short version of the Crowne and Marlowe (1960) social desirability scale with true and false response options was used. Employees were requested to indicate whether the statements describe themselves. Examples of statements are "When I don't know something, I don't at all mind admitting it" and "There have been occasions when I felt like smashing things." A score of 0 was given to the true and 1 to the false option. We reverse coded the negative statements and computed the mean score and standard deviation. The mean score was low $(M=$ $4.43, S D=1.66)$, hence indicating a low response bias.

\section{Data Analysis}

Structural Equation Modelling (SEM) was used to test the model fit of the data and prior to the data analysis, all the assumptions of inferential statistics were satisfied as suggested by Hair et al. (2010). With regards to sample size, Kline (2011) suggested that, the adequate sample size for SEM analysis should be at least 200 . We evaluated the assumption of normality for each univariate distribution of the variables based on the skewness and kurtosis values. Then, the descriptive statistics and correlation coefficients were calculated.

The model fit (both the measurement and structural models) were evaluated using the following fit indices. The Carmines-McIver index also known as relative chi-square $\left(\chi^{2} / \mathrm{df}\right)$ index indicates model fit if the value is between 2 and 3. For the Comparative Fit Index (CFI), Incremental Fit Index (IFI), Normed Fit Index (NFI) and Tucker-Lewis Coefficient Index (TLI), a value closer to 1 shows a good model fit, with a value of 0.9 indicating the typical threshold for good fit. The value of Root Mean Square Error of Approximation (RMSEA) indicates the goodness of fit of the proposed model in relation to the covariance matrix of the population. A value of less than 0.08 indicates a good fit. 


\section{Results}

\section{Participant Profile}

The participants comprised of $160(61.3 \%)$ females and $101(38.7 \%)$ males ranging in age from 22 to $59(M$ $=32.9, \mathrm{SD}=7.77)$. In terms of job category, $49.0 \%$ were in the executive and $51.0 \%$ non-executive category.

\section{Descriptive Statistics and Intercorrelations}

Table 1 shows the means, standard deviations and correlations of the studied variables. The correlation coefficients of relationships between variables are all less than the threshold (0.65) suggested by Tabachnick and Fidell (2013) for multicollinearity.

\section{Measurement Model}

The construct reliabilities were 0.94 for job stress, 0.89 for emotional stability and 0.98 for WDB. The convergent validity of all the constructs were confirmed since the reliability values met the minimum requirement $(\geq 0.70)$ (Hair et al., 2010). The Average Variance Extracted (AVE) for job stress was 0.65 , for emotional stability was 0.62 and for WDB was 0.76 . All the AVE values met the minimum requirement of 0.50 (Hair et al., 2010).

\section{Goodness-of-Fit of Measurement Model}

The fit indices of the measurement model were acceptable with $\chi^{2}=569.87(\mathrm{df}=246), \mathrm{p}=0.000, \mathrm{CFI}=$ 0.95 , IFI $=0.95$, NFI $=0.91$ and TLI $=0.94$, RMSEA $=$ 0.07 . The fit indices were acceptable $(>0.9)$, with $\chi^{2} / \mathrm{df}=$ $2.32(<3)$ and the RMSEA value was less than 0.08. Based on these indices, the hypothesized measurement model fit the collected data well. Thus, the conceptual distinctiveness of the measuring scales in this study was established.

\section{Testing of Hypotheses}

In Hypothesis 1, it is expected that job stress is correlated positively with WDB. To test this hypothesis, first, we examined the direct structural model for the relationship between job stress and WDB. The model's standardized regression coefficients $(\beta)$ and $\mathrm{p}$ values were computed to test the hypothesis. The direct model indicates a significant linkage $(\beta=0.30, \mathrm{p}=0.000)$ between job stress and WDB.

Hypothesis 2 predicted that emotional stability would moderate the relationship of job stress with WDB. Specifically, it was anticipated that the stress-deviance linkage would be stronger for employees low in emotional stability than for employees high in emotional stability. Based on emotional stability the sample was classified into two groups: High emotional stability, $\mathrm{n}=$ 125 and low emotional stability, $\mathrm{n}=136$. The structural model revealed good fit: Chi-square $=245.48, \mathrm{df}=174$, $\mathrm{p}=0.000 ; \mathrm{GFI}=0.89, \mathrm{IFI}=0.99, \mathrm{TLI}=0.98, \mathrm{CFI}=$ 0.99 and $\mathrm{RMSEA}=0.04$.
Table 1. Descriptive statistics and correlation coefficients

\begin{tabular}{llllll}
\hline Variable & $M$ & $S D$ & 1 & 2 & 3 \\
\hline 1. Job stress & 3.91 & 1.46 & & & \\
2. Emotional stability & 4.04 & 1.44 & $-0.47 * * *$ & \\
3. WDB & 2.70 & 1.71 & $0.30^{* * *}$ & $-0.60 * * *$ \\
\hline
\end{tabular}

Table 2. Moderating effect of emotional stability on the stressdeviance linkage

\begin{tabular}{lccc}
\hline Emotional stability & $\beta$ & $\mathrm{p}$ & $\mathrm{CR}$ \\
\hline Low emotional stability & 0.37 & 0.02 & 2.35 \\
High emotional stability & -0.19 & 0.04 & -2.02 \\
\hline
\end{tabular}

The findings indicate that the linkage between job stress and WDB in the unconstrained model (for low emotional stability group) is significant and positive ( $\beta=$ $0.37, \mathrm{CR}=2.35, \mathrm{p}=0.02$ ) but in the unconstrained model (for high emotional stability group) the results indicate that the same hypothesized path is significant but negative $(\beta=-0.19, \mathrm{CR}=-2.02, \mathrm{p}=0.04)$ (Table 2). As suggested by Hair et al. (2010) when standardized regression weights for both groups are significant with one positive while the other negative, the hypothesis on the moderating effect is supported. Hence, emotional stability significantly moderated the linkage between job stress and WDB. The impact of job stress on WDB between employees with low and high emotional stability differs significantly. Thus, Hypothesis 2 is supported.

\section{Discussion}

A moderation model was tested with job stress as the independent variable, WDB as the dependent variable and emotional stability as the moderator. We found that job stress was significantly related with WDB, thus supporting Hypothesis 1. Similar results were reported by, for example, Ugrin et al. (2008; Roberts et al., 2011). The results of this study are in support of the GST which suggests that strainful events resulting in stressful experiences tend to lead individuals to display deviant behavior.

As predicted, we found support for emotional stability as the moderator of the stress-deviance linkage. Our results indicate that job stress positively predicted WDB for employees with low emotional stability but not employees with high emotional stability. In other words, the engagement in WDB due to job stress varies with different dispositional characteristics. Our results are in support of Hypothesis 3 which postulates that emotional stability moderates the effect of job stress on WDB. In other words, emotional stability may prevent or reduce an employee from reacting to stressful experience in an uncivil manner. The results are in line with the integrated general model of WDB proposed by Nair and Bhatnagar (2011), in which besides organizational factors, individual factors including dispositional factors are associated with WDB. Although, low emotional stability 
is associated with impulsivity and impulsivity is associated with deviant behaviors in various situations (Verdejo-Garcíaa et al., 2007), the experience of increased job stress would increase WDB only among employees who are less emotionally stable. In accordance with the conservation of resources theory, emotional stability is a resource which can be utilized to reduce behavioral strain. The results support earlier studies which revealed that the lack of emotional stability leads to engagement in WDB (Gonzalez-Mulé et al., 2013; Hudson et al., 2012; Kluemper et al., 2015). Less emotionally stable individuals are more likely to encounter negative emotional states, such as anxiety, depression and anger that could trigger them to behave deviantly under stress and the behaviors displayed include behaviors such as tardiness, absenteeism and withholding effort. However, interestingly, among employees with high emotional stability the effect of job stress on WDB is not significant. The results demonstrate that employees with low and high emotional stability are differentially motivated to act deviant.

Overall, the findings of this study have significant implications in terms of theory and practice. Agnew's GST and the integrated general model of deviant behavior served as the theoretical bases for examining the stress-deviance linkage, as well as the moderating role of emotional stability. Our findings point to the important role of employee emotional stability in reducing WDB. Employees who can be calm and stable under pressure and hence less inclined to experience negative emotions, or are more able to control their negative emotions would have less tendency towards deviant acts as a means to illegitimately channel negative emotions, even when they experience high levels of stress at work.

Furthermore, the findings are in support of the integrated general model by Nair and Bhatnagar (2011) who proposed that other than job-related factors, individual-related factors including personality factors such as emotional stability could be linked to WDB. The findings help explain the stress-deviance linkage and demonstrate how the linkage is moderated by the personality trait, emotional stability. Theoretically, the findings of this present study suggest that a personality trait such as emotional stability serves as one of the important factors that shapes employee behavior. The results on employee emotional stability and its interaction with job stress resulting in a significant impact on deviant behavior at the workplace suggest the pertinent inclusion of emotional stability as a moderator in WDB model involving stress. The results also indicate that like other behaviors, WDB can be predicted by personality factors. Hence, this study contributes to the broader knowledge about the interaction of personality and situational experiences at work in determining behaviors.
Recognizing that human resource practices and organizational support play critical roles in influencing employee behavior (Asgari et al., 2008; Babaei et al., 2012), our study provides a few possible practical suggestions on how employers can reduce employee engagement in WDB, which tends to be costly for organizations as well as employees. First, preventive organizational policies and practices should be planned so as to help reduce employees' experience of stress, since employees who experience reduced amount of stress are less disposed to engagement in WDB than those who experience greater stress. There is a need to assess work load of employees as a possible source of stress or stressor (Shultz et al., 2010). Second, given the significance of emotional stability in reducing WDB, the findings may have implications on recruitment of employees. For example, when selecting potential employees, practitioners may screen for emotional stability besides knowledge, abilities and skills. Hiring employees with higher levels of emotional stability is important for practitioners as our study suggests that job stress is less threatening, among emotionally stable employees since there is no significant likelihood of stressful situations leading to WDB.

Although employers cannot directly influence employee dispositional characteristics, the use of effective selection tools with emotional stability as one of the criteria may improve the possibility of recruiting individuals who are less likely to exhibit deviant behavior due to job stress. It is also probably beneficial that employers hire individuals who possess self-control because they tend to manage or regulate well their negative emotional reactions when encountering less than ideal situations. Even though there has been increasing interest in and progress on the effect of dispositional factors on employee behavior (Linton and Power, 2013; Michel and Bowling, 2013; Grijalva and Newman, 2015), many questions have yet to be answered, as indicated in the argument on the status of studies with respect to personality in personnel recruitment (Morgeson et al., 2007; Ones et al., 2007; Tett and Christiansen, 2007). Additionally, providing training to employees in emotion regulation when under stress may be useful. There is also a need to pay attention to other possible environmental influences from supervisors, colleagues and the organizational climate on employees' levels of stress. If necessary, organizations could intervene by reducing factors that could negatively influence employees' experience of stress.

\section{Possible Limitations and Future Directions}

This present study has several possible limitations. Our results may be predisposed to problems related to common method variance since the data were acquired through self-reports. However, since our study deals with a personality trait, emotional stability and WDB, 
self-reports are considered acceptable as means to measure the study constructs. Moreover, Spector et al. (2006) claimed that the issue related to common method variance has been mostly exaggerated. In this present study we argued that there are numerous reasons a common method bias could not be a major limitation with regard to social desirability response. First, the anonymous data collected perhaps reduced the problem of response bias. Second, the social desirability test using the short version scale by Crowne and Marlowe (1960) produced a low response bias mean score of 4.42 $(S D=1.66)$. Third, the result of a meta-analysis conducted by Berry et al. (2012) revealed that there was no significant difference in the relationships between self-report WDB and other-reported WDB with a number of common correlates. This indicated that, using self-reported data for WDB had no significant effect on the relationships between WDB and other variables.

This study specifically focused on the influence of job stress on WDB. Perhaps emotional stability influenced the relationships between job stress and other outcomes. Job stress might result in a significant relationship with, for instance, employee turnover intention (Bridger et al., 2013; Thorsteinsson et al., 2014) and job dissatisfaction (Cheng et al., 2014).

The study sample posed another limitation since it consisted of only Malaysian public service sector employees. Hence, the findings may not be generalized to private service sector employees. We therefore recommend that studies be conducted on private service industries to endorse the generalizability of the findings.

\section{Conclusion}

Emotional stability serves as a buffer for the impact of job stress on employee deviant behavior. The stressdeviance linkage is stronger among employees with low emotional stability than those with high emotional stability. The present study contributes to the extant literature on stress and deviance at work by demonstrating how emotional stability moderates the stress-deviance linkage. Further testing of other variables that may interact with stress to reduce deviance at work will not only contribute to the advancement of research on workplace deviance but will also provide human resource management practitioners with insights on how to overcome this rampant and costly problem.

\section{Acknowledgement}

This work was supported by Universiti Putra Malaysia (Project No. 06-02-12-2251RU). The authors would like to thank the University for supporting this work.

\section{Author's Contributions}

All authors contributed considerably to this work.

\section{Conflict of Interest}

There is no conflict of interest with regard to the publication of this work.

\section{Ethics}

The originality of this work is confirmed by the authors. The authors also confirm that this work has not been published elsewhere.

\section{References}

Agnew, R., 2006. General Strain Theory: Current status and Directions for Further Research. In: Taking Stock: The Status of Criminological Theory, Advances in Criminological Theory, Cullen, F.T., J.P. Wright and K.R. Blevins (Eds.), Transaction, New Brunswick, NJ, pp: 101-126.

Anderson, S.E., B.S. Coffey and R.T. Byerly, 2002. Formal organizational initiatives and informal workplace practices: Links to work-life conflict and job-related outcomes. J. Manage., 28: 787-810. DOI: $10.1177 / 014920630202800605$

Appelbaum, S.H., G.D. Iaconi and A. Matousek, 2007. Positive and negative deviant workplace behaviors: Causes, impact and solutions. Corp Gov., 7: 86-598. DOI: $10.1108 / 14720700710827176$

Asgari, A., A.D. Silong, A. Ahmad and B.A. Samah, 2008. The relationship between organizational characteristics, task characteristics, cultural context and organizational citizenship behaviors. Eur. J. Econ. Finance Admin. Sci., 13: 94-107.

Babaei, D., A. Ahmad, K. Idris, Z. Omar and H. Rahimian, 2012. The impact of human resource practices and organizational citizenship behaviors on firm performance. Am. J. Applied Sci., 9: 47-53. DOI: 10.3844/ajassp.2012.1.6

Berry, C.M., A.M. Lelchook and M.A. Clark, 2012. A meta-analysis of the interrelationships between employee lateness, absenteeism and turnover: Implications for models of withdrawal behavior. J. Organ. Behav., 33: 678-699. DOI: 10.1002/job.778

Biron, M., 2010. Negative reciprocity and the association between perceived ethical norms and employee misbehaviour. Hum. Relat., 63: 875-897.

Bridger, R.S., A.J. Day and K. Morton, 2013. Occupational stress and employee turnover. Ergonomics, 56: 1629-1639. DOI: 10.1080/00140139.2013.836251

Cheng, C.Y., H.M. Tsai, C.H. Chang and S.R. Liou, 2014. New graduate nurses' clinical competence, clinical stress and intention to leave: A longitudinal study in Taiwan. Sci. World J., 2014: 1-9. DOI: $10.1155 / 2014 / 748389$ 
Costa, P. and R. MacCrae, 1992. The five factor model of personality and its relevance to personality disorders. J. Pers. Disord., 6: 343-359. DOI: $10.1521 /$ pedi.1992.6.4.343

Crowne, D.P. and D. Marlowe, 1960. A new scale of social desirability independent of psychopathology. J. Consul. Psychol., 24: 349-354. DOI: $10.1037 / \mathrm{h} 0047358$

Dalal, R.S., 2005. A meta-analysis of the relationship between organizational citizenship behavior and counterproductive work behavior. J. Applied Psychol., 90: 1241-1255. DOI: 10.1037/0021-9010.90.6.1241

Demir, M., 2011. Effects of organizational justice, trust and commitment on employees' deviant behavior. Anatolia, 22: 204-221.

DOI: 10.1080/13032917.2011.597934

Fida, R., M. Paciello, C. Tramontano, R.G. Fontaine and C. Barbaranelli et al., 2015. An integrative approach to understanding counterproductive work behavior: The roles of stressors, negative emotions and moral disengagement. J. Bus. Ethics, 130: 131-144. DOI: $10.1007 / \mathrm{s} 10551-014-2209-5$

Garrett, R.K. and N.D. James, 2008. On cyberslacking: Workplace status and personal Internet use at work. Cyberpsychol. Behavior., 11: 287-292. DOI: 10.1089/cpb.2007.0146

Gill, H., J.P. Meyer, K. Lee, K.H. Shin and C.Y. Yoon, 2011. Affective and continuance commitment and their relations with deviant workplace behaviors in Korea. Asia Pacific J. Manage., 28: 595-607. DOI: $10.1007 / \mathrm{s} 10490-009-9165-0$

Gonzalez-Mulé, E., D.S. DeGeest, C.E. Kiersch and M.K. Mount, 2013. Gender differences in personality predictors of counterproductive behavior. J. Manage. Psychol., 28: 333-353. DOI: 10.1108/JMP-12-2012-0397

Greenberg, J., 2010. Managing Behaviour in Organizations. 1st Edn., Prentice Hall, Upper Saddle River, NJ.

Grijalva, E. and D.A. Newman, 2015. Narcissism and Counterproductive Work Behavior (CWB): Meta-analysis and consideration of collectivist culture, big five personality and narcissism's facet structure. Applied Psychol., 64; 93-126. DOI: 10.1111/apps.12025

Hair, J.F., W.C. Black, B.J. Babin and R.E. Anderson, 2010. Multivariate Data Analysis. 7th Edn., Prentice Hall, Upper Saddle River, NJ.

Hay, C., R. Meldrum and K. Mann, 2010. Traditional bullying, cyber bullying and deviance: A general strain theory approach. J. Contemp. Crim. Just., 26: 130-147. DOI: $10.1177 / 1043986209359557$

Hudson, N.W., B.W. Roberts and J. Lodi-Smith, 2012. Personality trait development and social investment in work. J. Res. Pers., 46: 334-344. DOI: $10.1016 /$ j.jrp.2012.03.002
Kline, R.B., 2011. Convergence of Structural Equation Modeling and Multilevel Modeling. In Handbook of Methodological Innovation in Social Research Methods, Williams, M. and W.P. Vogt (Eds.), Sage, London, pp: 562-589.

Kluemper, D.H., B.D. McLarty and M.N. Bing, 2015. Acquaintance ratings of the big five personality traits: Incremental validity beyond and interactive effects with self-reports in the prediction of workplace deviance. J. Applied Psychol., 100: 237-248. DOI: $10.1037 / \mathrm{a} 0037810$

Linton, D.K. and J.L. Power, 2013. The personality traits of workplace bullies are often shared by their victims: Is there a dark side to victims? Pers. Indiv. Differ., 54: 738-743. DOI: 10.1016/j.paid.2012.11.026

McVicar, A., 2003. Workplace stress in nursing: A literature review. J. Adv. Nur., 44: 633-642. DOI: $10.1046 /$ j.0309-2402.2003.02853.x

Michel, J.S. and N.A. Bowling, 2013. Does dispositional aggression feed the narcissistic response? The role of narcissism and aggression in the prediction of job attitudes and counterproductive work behaviors. J. Bus. Psychol., 28: 93-105.

DOI: $10.1007 / \mathrm{s} 10869-012-9265-6$

Morgeson, F.P., M.A. Campion, R.L. Dipboye, J.R. Hollenbeck and K. Murphy et al., 2007. Reconsidering the use of personality tests in personnel selection contexts. Pers. Psychol., 60: 683-729. DOI: 10.1111/j.1744-6570.2007.00089.x

Nair, N. and D. Bhatnagar, 2011. Understanding workplace deviant behavior in nonprofit organizations: Towards an integrative conceptual framework. Nonprof. Manage. Leadership, 21: 289-309. DOI: $10.1002 / \mathrm{nml} .20026$

Nasir, M. and A. Bashir, 2012. Examining workplace deviance in public sector organizations of Pakistan. Int. J. Soc. Econ., 9: 240-253. DOI: $10.1108 / 03068291211205677$

Nielsen, M.B. and S. Knardahl, 2015. Is workplace bullying related to the personality traits of victims? A two-year prospective study. Work Stress, 29: 128-149. DOI: $10.1080 / 02678373.2015 .1032383$

Ones, D.S., S. Dilchert, C. Viswesvaran and T.A. Judge, 2007. In support of personality assessment in organizational settings. Pers. Psychol., 60: 995-1027. DOI: $10.1111 /$ j.1744-6570.2007.00099.x

O'Neill, T.A. and S.E. Hastings, 2011. Explaining workplace deviance behavior with more than just the "Big Five". Pers. Indiv. Differ., 50: 268-273. DOI: $10.1016 /$ j.paid.2010.10.001

Penney, L.M., E.M. Hunter and S.J. Perry, 2011. Personality and CWB: Using conservation of resources theory to narrow the profile of deviant employees. J. Occup. Organ. Psych., 84: 58-77. DOI: $10.1111 /$ j.2044-8325.2010.02007.x 
Piquero, N.L. and T.E. Moffitt, 2014. Can childhood factors predict workplace deviance? Just. Q., 31: 664-692. DOI: 10.1080/07418825.2012.661446

PCBAR, 2011. Public complaints bureau annual report.

Resick, C.J., M.B. Hargis, P. Shao and S.B. Dust, 2013. Ethical leadership, moral equity judgments and discretionary workplace behavior. Hum. Relat., 66: 951-972. DOI: 10.1177/0018726713481633

Roberts, S., L. Scherer and C. Bowyer, 2011. Job stress and incivility: What role does psychological capital play? J. Leadersh. Organ. Stud., 18: 449-458. DOI: $10.1177 / 1548051811409044$

Robinson, S.L. and R.J. Bennett, 2000. Development of a measure of workplace deviance. J. Applied Psychol., 85: 349-60. DOI: 10.1037/0021-9010.85.3.349

Sackett, P.R., 2002. The structure of counterproductive work behaviors: Dimensionality and relationships with facets of job performance. Int. J. Select. Assess., 10: 5-11. DOI: 10.1111/1468-2389.00189

Saucier, G., 1994. Mini-markers: A brief version of Goldberg's unipolar big-Five markers. J. Pers. Assess., 63: 506-516. DOI: 10.1207/s15327752jpa6303_8

Schieman, S. and A. Bierman, 2011. The Role of Divine Beliefs in Stress Processes. In Toward a Sociological Theory of Religion and Health, Blasi, A.J. (Ed.), Brill, Blasi Leiden, pp: 45-68.

Shultz, K.S., M. Wang and D.A. Olson, 2010. Role overload and underload in relation to occupational stress and health. Stress Health, 26: 99-111. DOI: $10.1002 /$ smi.1268

Spector, P.E., S. Fox, L.M. Penney, K. Bruursema and A. Goh et al., 2006. The dimensionality of counterproductivity: Are all counterproductive behaviors created equal? J. Vocat. Behav., 68: 446-460. DOI: 10.1016/j.jvb.2005.10.005
Tabachnick, B.G. and L.S. Fidell, 2013. Using Multivariate Statistics. 6th Edn., Pearson, Boston.

Tett, R.P. and N.D. Christiansen, 2007. Personality tests at the crossroads: A response to Morgeson, Campion, Dipboye, Hollenbeck, Murphy and Schmitt. Pers. Psychol., 60: 967-993. DOI: $10.1111 / \mathrm{j} .1744-6570.2007 .00098 . \mathrm{x}$

Thorsteinsson, E., R. Brown and C. Richards, 2014. The Relationship between work-stress, psychological stress and staff health and work outcomes in office workers. Psychology, 5: 1301-1311. DOI: $10.4236 /$ psych.2014.510141

Tourangeau, R. and Y. Ting, 2007. Sensitive questions in surveys. Psychol. Bull., 133: 859-883. DOI: 10.1037/0033-2909.133.5.859

Tuna, M., I. Ghazzawi, M. Yeşiltaş, A.A. Tuna and S. Arslan, 2016. The effects of the perceived external prestige of the organization on employee deviant workplace behavior: The mediating role of job satisfaction. Int. J. Contemp. Hospit. Manage., 28: 366-396. DOI: 10.1108/IJCHM-04-2014-0182

Ugrin, J.C., M.D. Odum and J.M. Pearson, 2008. Exploring the importance of mentoring for new scholars: A social exchange perspective. J. Inf. Syst. Educ., 19: 343-350.

Verdejo-Garcíaa, A., A. Becharab, E.C. Recknord and M. Pérez-Garcíae, 2007. Negative emotion-driven impulsivity predicts substance dependence problems. Drug Alcohol Depen., 91: 213-219. DOI: 10.1016/j.drugalcdep.2007.05.025

Wei, F. and S. Si, 2013. Tit for tat? Abusive supervision and counterproductive work behaviors: The moderating effects of locus of control and perceived mobility. Asia Pacific J. Manage., 30: 281-296. DOI: $10.1007 / \mathrm{s} 10490-011-9251-y$ 